\title{
The Cold Fusion Phenomenon - Nuclear Reactions in the CF Materials at Around Room Temperature
}

\author{
Hideo Kozima \\ Cold Fusion Research Laboratory, Research Division, Cold Fusion Research Laboratory, Shizuoka, Japan
}

Email address:

hjrfq930@ybb.ne.jp

To cite this article:

Hideo Kozima. The Cold Fusion Phenomenon - Nuclear Reactions in the CF Materials at Around Room Temperature. International Journal of High Energy Physics. Vol. 8, No. 1, 2021, pp. 1-12. doi: 10.11648/j.ijhep.20210801.11

Received: May 12, 2021; Accepted: May 31, 2021; Published: June 7, 2021

\begin{abstract}
Since the discovery of nuclear reactions in $\mathrm{PdD}_{\mathrm{x}}$ alloys at around room temperature in 1989 , there have been accumulated very many experimental data sets showing existence of nuclear reactions in solid materials composed of transition metals and occluded hydrogen isotopes (let us call them the $C F$ materials, for short) resulting in various nuclear products such as neutrons, tritium, transmuted nuclei, and others accompanied with large excess energies at relatively low temperatures up to $1000^{\circ} \mathrm{C}$ (let us call these whole events the cold fusion phenomenon (CFP), for short). As the cause of these nuclear reactions in the CFP, we have to accept the existence of the interactions between nuclei in the CF material through the nuclear force (let us call this interaction the nuclear-force interaction, for short) recognized its existence in the nucleus in the nuclear physics. We can classify the CF materials, i.e. materials where CFP occurs, into three groups: (1) metallic material including transition-metal hydrides (e.g. $\left.\mathrm{NiH}_{\mathrm{x}}, \mathrm{AuH}_{\mathrm{x}}\right)$ and deuterides (e.g. $\left.\mathrm{PdD}_{\mathrm{x}}, \mathrm{TiD}_{\mathrm{x}}\right)$, (2) carbonic material including hydrogen graphite $\left(\mathrm{HC}_{\mathrm{x}}\right)$ and $\mathrm{XLPE}$ (cross-linked polyethylene) and (3) biological material including microorganisms, microbial cultures and biological tissues or organs. We will explain the characteristics of the CFP observed in each group in this paper. The nuclear reactions in the CF material gives rise to production of new particles from neutron, triton, and new nuclei with proton numbers $Z$ up to 83 accompanying enormous excess energy. In addition to these events, there occurs the stabilization of unstable nuclei, including the decay-time shortening of radioactive nuclei, which is especially interesting to apply it to treat hazardous nuclear waste produced by the nuclear power plant. Finally, we give an overview of the CFP in relation to the solid state-nuclear physics and the solid state-nuclear chemistry where the nuclear-force interaction may play important roles to explain the riddles found but not given appropriate explanations in these old sciences hitherto.
\end{abstract}

Keywords: Biotransmutation, Cold Fusion Phenomenon, Nuclear Reaction, Nuclear Transmutation, Solid State-Nuclear Science, Transition Metal Hydrides

\section{Introduction - Nuclear Reactions in the CF Materials}

In more than 30 years since the discovery of nuclear reactions in $\mathrm{PdD}_{\mathrm{x}}$ alloys in 1989 ([1], and e.g., [2, 3, 4]), there have been accumulated very many experimental data sets showing existence of nuclear reactions in solid materials composed of transition metals and occluded hydrogen isotopes (let us call them the $C F$ materials, for short) resulting in various nuclear products such as neutrons, tritons, transmuted nuclei, and others accompanied with large excess energies at relatively low temperatures up to $1000^{\circ} \mathrm{C}$ (let us call these whole events the cold fusion phenomenon (CFP), for short). It will be persuasive to cite several experimental data obtained in recent years (e.g., $[5,6,7,8]$ ) to show that the field of the CFP is progressing even now after 30 years of its discovery.

In contrast to the large quantity and the excellent quality of the evidence of the nuclear reactions in the CF material, there are too low evaluations for them in the world of the natural sciences. The causes of this social phenomenon might be various but the most important one in them is, in our impression, the lack of possible unified explanations for the wide variety of events in the CFP outside of established fields of sciences developed in $20^{\text {th }}$ century.

To explain these nuclear reactions related to the events in the CFP, it is clear that we have to accept the existence of the 
interactions between nuclei in the $\mathrm{CF}$ material through the nuclear force (let us call this interaction the nuclear-force interaction, for short) recognized its existence in the nuclear physics.

In this paper, we introduce the whole field of the cold fusion phenomenon (CFP) and a possible approach to give a unified explanation of the whole experimental data observed there to promote the investigation of the possible new field of the science between two big fields, nuclear physics and solid state physics, developed in these almost 100 years. In Section 2, we give a brief summary of the events of the CFP. In Section 3, we introduce our phenomenological approach with the TNCF model and give short references for its quantum mechanical foundations. The nuclear transmutations in the CF materials composed of metals and alloys are discussed in Section 4 and those composed of polymers and biological systems are discussed in Section 5 . In Section 6, we give a short introduction to the new field of solid state-nuclear sciences where the nuclear-force interaction discovered by the CFP will contribute to develop in near future. There are many riddles found but not given appropriate explanations hitherto. The nuclear-force interaction which has not noticed its existence until now will play decisive role to resolve these riddles.

\section{Summary of the Cold Fusion Phenomenon}

We summarize the nuclear transmutations observed in the cold fusion phenomenon (CFP). The CF materials, i.e. materials where CFP occurs, are classified into three groups: (1) metallic material including transition-metal hydrides (e.g. NiHx, AuHx) and deuterides (e.g. PdDx, TiDx), (2) carbonic material including hydrogen graphite $(\mathrm{HCx})$ and XLPE (cross-linked polyethylene) and (3) biological material including microorganisms, microbial cultures and biological tissues or organs. We will explain the characteristics of the CFP observed in these groups using our phenomenological approach with the TNCF model in this paper.

In the explanation of the CFP in this paper, we put a special emphasis on the following characteristics of the CFP observed in the third group. The stabilization of unstable nuclei and the decay-time shortening of radioactive nuclei are especially interesting from the viewpoint of application to treat hazardous nuclear waste produced by nuclear power plant. A characteristic of biological systems, wherein selective adsorption of specific ions occurs, seems especially useful for this purpose. If we have a microorganism or microbial culture absorbing an ion of a radioactive element selectively, we can remediate the radioactivity of the ion by biotransmutation.

Even if the neutrons and tritons measured in the experiments by Fleischmann et al. [1] are not persuasive due to their unsatisfactory detection techniques, the observation of excess energy by them and the detection of helium in their samples by experts [2] had shown clear evidence of the nuclear reactions generating helium and accompanying large excess energy inexplicable by other sources in their experiments.

The nuclear reactions generating tritium and neutron in the CF materials had been confirmed by many investigators in one or two years after the first experiment by Fleischmann et al. We can cite several papers where are detected tritium in deuterated CF materials as follows [3, 9, $10,11]$ and [12].

We tabulated some characteristics of the CFP in Table 1. In the table, the CF materials are divided into host solids (in the row 1 ) and agents (in the row 2) to indicate clearly possible opponents of the reaction with the "trapped neutrons" assumed in out TNCF model $[13,14]$.

Table 1. System and Obtained Evidence of the CFP: Host solids, agents, experimental methods, direct and indirect evidence, cumulative and dissipative observables are tabulated. $Q$ and NT express excess energy and the nuclear transmutation, respectively. Direct evidence of nuclear reactions in the CFP are dependences of reaction products on their energy $(\varepsilon)$ and position $(r)$, decrease of decay constants of radioactive nuclides, decrease of fission threshold energy of compound nuclei.

\begin{tabular}{|c|c|}
\hline Host solids & $\begin{array}{l}\mathrm{C}, \mathrm{Pd}, \mathrm{Ti}, \mathrm{Ni}, \mathrm{Au}, \mathrm{Pt}, \mathrm{KCl}+\mathrm{LiCl}, \mathrm{ReBa}_{2} \mathrm{Cu}_{3} \mathrm{O}_{7}, \mathrm{Na}_{\mathrm{x}} \mathrm{WO}_{3}, \mathrm{KD}_{2} \mathrm{PO}_{4}, \mathrm{TGS} \text { (triglycine sulfate), } \mathrm{SrCe}_{\mathrm{a}} \mathrm{Y}_{\mathrm{b}} \mathrm{NB}_{\mathrm{c}} \mathrm{O}_{\mathrm{d}}, \mathrm{XLPE}(\mathrm{cross} \\
\text { linked polyethylene), Biological Systems (microbial cultures) }\end{array}$ \\
\hline Agents & $n, d, p,{ }_{3}^{6} \mathrm{Li},{ }_{3}^{10} \mathrm{~B},{ }_{6}^{12} \mathrm{C},{ }_{19}^{39} \mathrm{~K},{ }_{37}^{85} \mathrm{Rb},{ }_{37}^{87} \mathrm{Rb}$ \\
\hline Experiments & lectrolysis, Liquid contact, Gas discharge, Gas contact \\
\hline $\begin{array}{l}\text { Direct evidence of nuclear } \\
\text { reactions }\end{array}$ & $\begin{array}{l}\text { Gamma ray spectrum } \gamma(\varepsilon) \text {, Neutron energy spectrum } n(\varepsilon) \text {, } \\
\text { Space distribution of NT products NT(r), } \\
\text { Stabilization of unstable nuclei (Decrease of decay constants), Lowering of fission threshold energy }\end{array}$ \\
\hline $\begin{array}{l}\text { Indirect evidence of } \\
\text { nuclear reactions }\end{array}$ & $\begin{array}{l}\text { Excess energy } Q \text {, Number of neutrons } N_{\mathrm{n}} \text {, Amounts of tritium atom } N_{\mathrm{t}} \text {, helium-4 atom* } N_{\mathrm{He} 4}, \mathrm{NT} \text { products }\left(\mathrm{NT}_{\mathrm{D}}, \mathrm{NT}_{\mathrm{F}}, \mathrm{NT}_{\mathrm{A}}\right) \text {, } \\
\text { X-ray spectrum } \mathrm{X}(\varepsilon)\end{array}$ \\
\hline Cumulative observables & Number of transmuted nuclei NT( $r)$, amount of tritium atom $N_{\mathrm{t}}$, amount of helium- $4 * N_{\mathrm{He} 4}$, \\
\hline Dissipative observables & $\begin{array}{l}\text { Excess energy } Q \text {, neutron energy spectrum } n(\varepsilon) \text {, energy spectrum of neutrons } N_{\mathrm{n}} \text {, Gamma ray spectrum } \gamma(\varepsilon) \text {, X-ray spectrum } \\
\mathrm{X}(\varepsilon) \text {, }\end{array}$ \\
\hline
\end{tabular}

It is interesting to see the ubiquitous appearance of the CFP in various CF materials as shown in the row 1 (host solids) of Table 1.

The almost all experimental data obtained in the CF materials, having a huge variety shown in Table 1 have consistently been explained by the phenomenological approach using the TNCF model as shown in our books $[13,14]$. 


\section{Phenomenological Approach and Its Foundation}

There are many routes of approaches to the problem showing apparent contradiction with the principles of the established sciences. One of the effective approaches to the cold fusion phenomenon showing several riddles inexplicable by the principles in the quantum physics is the phenomenological one using a model based on the experimental facts.

We have proposed a phenomenological approach using the TNCF (trapped neutron catalyzed fusion) model [15] and developed it further until 2006 ([13, 14], Appendices A2 and A3 in [16]).

The premises of the TNCF model have been investigated quantum mechanically using the idea of the neutron energy bands generated by the super-nuclear interaction between neutrons in different lattice nuclei mediated by interstitial protons/deuterons ([14], Appendix A3 in [16]).

We could find out the necessary and sufficient condition for the generation of the neutron energy bands explained above using the idea of self-organization in the complexity developed by the nonlinear dynamics [17]. The regular superlattice XY of host elements $\mathrm{X}$ at lattice points and occluded protons/deuterons $\mathrm{Y}$ at interstices is generated by the self-organization revealed by the nonlinear dynamics even if the average composition of the $\mathrm{CF}$ material is $\mathrm{X}_{\mathrm{x}} \mathrm{Y}_{\mathrm{y}}$ with $x \neq y$. in the situation where the material is an open, nonequilibrium, and multi-component systems ([17], Sections 3.8 and 3.9 in [18]).

The explanation of the characteristics of the experimental data in the CFP has been given by the TNCF model as follows.

\subsection{Nuclear Reactions in Free Space and in the CF Materials}

Reactions in free space supposed by Fleischmann et al. to be responsible to their experimental results are written down as follows $[1,19]$ :

$$
\begin{aligned}
d+d \rightarrow{ }_{2}^{4} \mathrm{He}^{*} \rightarrow t(1.01 \mathrm{MeV})+p(3.12 \mathrm{MeV}), \\
\rightarrow{ }_{2}^{3} \mathrm{He}(0.82 \mathrm{MeV})+n(2.45 \mathrm{MeV}), \\
\rightarrow{ }_{2}^{4} \mathrm{He}(0.08 \mathrm{MeV})+\gamma(23.8 \mathrm{MeV}) .
\end{aligned}
$$

The branching ratios of these reactions have been determined in the nuclear physics as $1: 1: 10^{-7}$ down to low energies of a few $\mathrm{keV}$.

Other nuclear reactions between light nuclei in free space are written down as follows.

$$
\begin{array}{r}
n+p=d(1.3 \mathrm{keV})+\gamma(2.2 \mathrm{MeV}) . \\
n+d=t(6.98 \mathrm{keV})+\gamma(6.25 \mathrm{MeV}) . \\
n+{ }_{3}^{6} \mathrm{Li}=t(2.7 \mathrm{MeV})+{ }_{2}^{4} \mathrm{He}(2.1 \mathrm{MeV}), \\
t+d={ }_{2}^{4} \mathrm{He}(3.5 \mathrm{MeV})+n(14.1 \mathrm{MeV}),
\end{array}
$$

Unified Explanation of the CFP by the Phenomenological Theory using the TNCF model is given by us in which the gamma in Eqs. (3), (4) and (5) in free space should be read as $\varphi$ 's (phonons excited by the reaction in contact with trapped neutrons) as explained below $[13,14,15,19,20]$.

According to the discussions for the phenomenological approach given in these books and papers, we have assumed that the gammas in the reactions (3), (4) and (5) in free space should be read as $\varphi$ 's (phonons excited in the CF materials by the fusion reactions in contact with trapped neutrons) in the CF material:

$$
\begin{gathered}
d+d={ }_{2}^{4} \mathrm{He}(0.08 \mathrm{MeV})+\varphi s^{\prime}+Q, \\
n+p=d+\varphi s^{\prime}+Q^{\prime}, \\
n+d=t+\varphi s^{\prime}+Q^{\prime},
\end{gathered}
$$

where $Q=23.8 \mathrm{MeV}, Q^{\prime}=2.2 \mathrm{MeV}$ and $Q^{\prime \prime}=6.25 \mathrm{MeV}$.

\subsection{Relations Between the Observed Number of Observables in the CFP Deduced by the TNCF Model}

There are several evidence showing the effectiveness of the TNCF model to give a unified explanation of the whole experimental data obtained in the CFP. One of the strong evidence of them is the explanation of the ratios of the observed numbers $N_{\mathrm{x}} / N_{\mathrm{y}}$ of observables $x$ and $y$ are explained consistently with the experimental values by assuming a value for the adjustable parameter $n_{\mathrm{n}}$ of the model.

Relations between Observed Values of Physical Quantities (p. 150 in [13], p. 76 in [14]).

$$
N_{\mathrm{Q}} \approx N_{\mathrm{t}} \approx 10^{7} N_{\mathrm{n}} \text {. }
$$

The lack of the quantitative reproducibility in the CFP has been explained by the concept of the complexity in the generation of the neutron energy bands [17].

The surface nature of the nuclear reactions in the CFP is explained by the nature of the neutron Bloch waves in the neutron energy bands. Neutrons in a neutron energy band in perfect superlattice do not interact neither with a lattice nucleus nor with a proton/deuteron but do interact with specific nuclei at disordered site in the CF material. The most popular disordered lattice nuclei exist at boundaries of the $\mathrm{CF}$ material which result in nuclear transmutations observed very often there in CF experiments [13, 14, 21].

Explanation of the distribution of transmuted nuclei in the CFP over the atomic number concordant with the natural abundance in the universe has been formulated as the First Law (Appendix A10 in [16, 22]).

\subsection{Quantum Mechanical Foundations of the TNCF Model}

The premises used to construct the TNCF model have been investigated quantum mechanically. The essence of the justification of the premises in the TNCF model has been given in our papers and books [14, 20,21]. There appears a possibility to realize the nuclear-force interaction between nucleons in the material when the wavefunctions of the occluded protons/deuterons have extension to overlap with the lattice nuclei as in the CF material such as $\mathrm{NiH}_{\mathrm{x}}$ and $\mathrm{PdD}_{\mathrm{x}}(x \lesssim 1)$. 


\section{Nuclear Transmutations in the CF Materials (1) - Metals and Their Alloys}

The nuclear transmutation, one of the characteristics of the nuclear reactions in the CFP, has shown peculiarity of the nuclear reactions in the $\mathrm{CF}$ materials inexplicable by simple two-body reactions like the $d-d$ fusion reactions assumed by the pioneers of the "cold fusion" reaction in 1989.

\subsection{Nuclear Transmutations}

The evidence of the nuclear reaction in the $\mathrm{CF}$ material resulting in the nuclear transmutation generating new nuclei with large nucleon numbers $A$ and emission of tritons and neutrons have been observed since 1989 until now as tabulated Tables 2 and 3 for the data until 1989 [13].

Table 2. $P d / D(H) / L i$ Systems. Neutron density $n_{n}$ and relations between the numbers $N_{x}$ of the event $x$ obtained by theoretical analysis of experimental data on the TNCF model $\left(N_{Q} \equiv Q(\mathrm{MeV}) / 5 \mathrm{MeV}\right)$. Typical value of the surface vs. volume ratio $\mathrm{S} / \mathrm{V}\left(\mathrm{cm}^{-1}\right)$ of the sample is tabulated, also (Table 11.2 in [13]). References in this table, e.g., Fleischmann et al. ${ }^{1)}$, are posted at the CFRL website: http://www.kozima-cfrl.com/Books/bookse/bookse01/referl.htm.

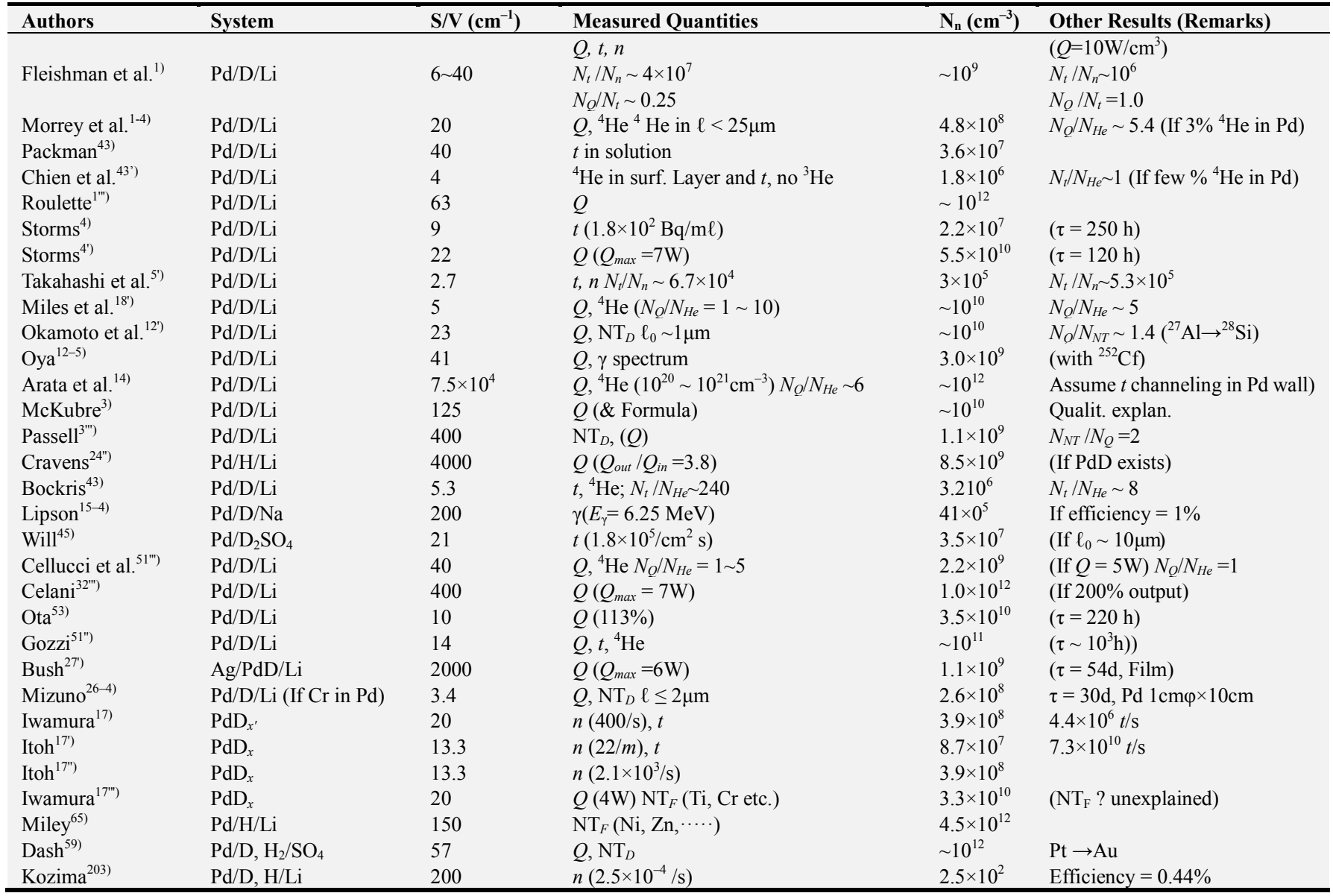

The nuclear transmutations observed since 1998 have been investigated and analyzed as published in our papers (Sec. 2.11 in $[14,19,22]$. These analyses were also successful as and consistent with the results summarized in the Tables 2 and 3.

Another extensive compilation of experimental data in the CFP had been given by E. Storms in his book published in 2007 [23].

There are several kinds of CF materials which we did not take up specifically until 2019. They include two kinds of materials; (1) the composite materials including alloys, ceramics, and polymers and (2) the compound materials with interfaces between several parts (materials supported by substrates, multi-layered materials, etc.) composing the system. The materials in the second group are (a) CF materials surrounded by liquids and gases, (b) those supported by substrates, (c) and those have multilayered structure. The experimental data obtained in these CF materials had been analyzed taking into the characteristics of these materials and published in the Proceedings of JCF21 [23, 24].

Table 3. $\mathrm{Ni} / \mathrm{H} / \mathrm{K}$ Systems $+\alpha$. Neutron density $n_{n}$ and relations between the numbers $N_{x}$ of the event $x$ obtained by theoretical analysis of experimental data on the $T N C F$ model $\left(N_{Q} \equiv Q(\mathrm{MeV}) / 5 \mathrm{MeV}\right)$. Typical value of the surface vs. volume ratio $\mathrm{S} / \mathrm{V}\left(\mathrm{cm}^{-1}\right)$ of the sample is tabulated, also (Table 11.3 in [13]). References in this table, e.g., Jones ${ }^{2}$, are posted at the CFRL website: http://www.kozima-cfrl.com/Books/bookse/bookse01/referl.htm

\begin{tabular}{|c|c|c|c|c|c|}
\hline Authors & System & $\mathrm{S} / \mathrm{V}\left(\mathrm{cm}^{-1}\right)$ & Measured Quantities & $n_{\mathrm{n}}\left(\mathrm{cm}^{-3}\right)$ & Other Results (Remarks) \\
\hline Jones $^{2)}$ & $\mathrm{Ti} / \mathrm{D} / \mathrm{Li}$ & 8.1 & $n(2.45 \mathrm{MeV})$ & $3.1 \times 0^{11}$ & \\
\hline Mills $^{25)}$ & $\mathrm{Ni} / \mathrm{H} / \mathrm{K}$ & 160 & $Q(0.13 \mathrm{~W})$ & $3.4 \times 10^{10}$ & \\
\hline
\end{tabular}




\begin{tabular}{|c|c|c|c|c|c|}
\hline Authors & System & $\mathrm{S} / \mathrm{V}\left(\mathrm{cm}^{-1}\right)$ & Measured Quantities & $n_{\mathrm{n}}\left(\mathrm{cm}^{-3}\right)$ & Other Results (Remarks) \\
\hline \multirow{2}{*}{ Bush $^{\left.27^{\prime}\right)}$} & $\mathrm{Ni} / \mathrm{H} / \mathrm{K}$ & $\sim 160$ & $\mathrm{NT}_{D}(\mathrm{Ca})$ & $5.3 \times 10^{10}$ & \multirow{2}{*}{$N_{Q} / N_{N T} 3.5$ if $\tau=0$ for ${ }^{40} \mathrm{~K}$} \\
\hline & $\mathrm{Ni} / \mathrm{H} / \mathrm{Na}$ & $\sim 160$ & $\mathrm{NT}_{D}(\mathrm{Mg})$ & $5.3 \times 10^{11}$ & \\
\hline$\left(\right.$ Bush $^{27 ")}$ & $\mathrm{Ni} / \mathrm{H} / \mathrm{Rb}$ & $\sim 10^{4}$ & $\mathrm{NT}_{D}(\mathrm{Sr})$ & $1.6 \times 10^{7}$ & $N_{Q} / N_{N T} \sim 3$ \\
\hline Savvatimova et al. ${ }^{\left.34^{\prime \prime}\right)}$ & $\mathrm{Pd} / \mathrm{D}_{2}$ & 100 & $\mathrm{NT}_{D}(\mathrm{Ag})$ & $9 \times 10^{10}$ & \\
\hline Bockris et al. $^{43-6)}$ & $\mathrm{Pd} / \mathrm{H} /$ & & $\mathrm{NT}_{F}(\mathrm{Mg}, \mathrm{Si}, \mathrm{Cs}, \mathrm{Fe}$, etc. in $1 \mu$ mlayer $)$ & $7.0 \times 10^{6}$ & Only Fe ( $10 \%$ of $\mathrm{Pd})$ is taken up. \\
\hline Alekseev $^{\left.44^{\prime}\right)}$ & $\mathrm{Mo} / \mathrm{D}_{2}$ & 4.1 & $t\left(\sim 10^{7} / \mathrm{s}\right)$ & $1.8 \times 10^{7}$ & (If MoD) \\
\hline Romodanov et al. ${ }^{\left.44^{\prime \prime}\right)}$ & $\mathrm{TiC} / \mathrm{D}$ & 4.1 & $t\left(\sim 10^{6} / \mathrm{s}\right)$ & $\sim 10^{6}$ & (D / Ti $\sim 0.5$ assumed $)$ \\
\hline Reifen-schweiler ${ }^{\left.38^{\prime}\right)}$ & $\mathrm{TiT}_{0.0035}$ & $7 \times 10^{5}$ & $\beta$ decay reduction & $1.1 \times 10^{9}$ & $\left(T=0 \sim 450^{\circ} \mathrm{C}\right)$ \\
\hline Dufour $^{7)}$ & $\begin{array}{l}\mathrm{Pd}, \mathrm{SS} / \mathrm{D}_{2} \\
\mathrm{Pd}, \mathrm{SS} / \mathrm{H}_{2}\end{array}$ & 48 & $Q, t, n$ & $\begin{array}{l}9.2 \times 10^{11} \\
4.0 \times 10^{9}\end{array}$ & (D ( $\mathrm{H}) \mathrm{Pd} \sim 1$ is assumed) \\
\hline Claytor $^{9)}$ & $\mathrm{Pd} / \mathrm{D}_{2}$ & 400 & $t(12.5 \mathrm{nCi} / \mathrm{h})$ & $1.6 \times 10^{13}$ & (If $\mathrm{D} / \mathrm{Pd} \sim 0.5)$ \\
\hline Srinivasan ${ }^{16)}$ & $\mathrm{Ti} / \mathrm{D}_{2}$ & 1500 & $t\left(t / d \sim 10^{-5}\right)$ & $1.9 \times 10^{8}$ & (Aged plate) \\
\hline De Ninno ${ }^{6}$ ) & $\mathrm{Ti} / \mathrm{D}_{2}$ & 440 & $n, t$ & $1.2 \times 10^{6}$ & $(\mathrm{D} / \mathrm{Ti}=1.1)$ \\
\hline Focardi ${ }^{23)}$ & $\mathrm{Ni} / \mathrm{H}_{2}$ & 8.2 & $Q$ & $3.0 \times 10^{12}$ & (If $\mathrm{N}_{\mathrm{P}}=10^{21}$ ) \\
\hline Oriani $^{52)}$ & $\mathrm{SrCeO}_{3} / \mathrm{D}_{2}$ & 22 & $Q \sim 0.7 \mathrm{~W}$ & $4.0 \times 10^{10}$ & $\mathrm{~V}=0.31 \mathrm{~cm}^{3}$ \\
\hline Notoya ${ }^{35 ")}$ & $\mathrm{Ni} / \mathrm{D}, \mathrm{H} / \mathrm{K}$ & $3.4 \times 10^{4}$ & $Q(0.9 \mathrm{~W}) t$ & $2.4 \times 10^{13}$ & (If $1 / 2 \mathrm{t}$ is in liquid) \\
\hline Notoya $^{35-4)}$ & $\mathrm{Ni} / \mathrm{D}, \mathrm{H} / \mathrm{K}$ & same & $\mathrm{NT}_{D}(\mathrm{Ca})$ & $1.4 \times 10^{9}$ & (Sintered Ni) \\
\hline Yamada $^{54)}$ & $\mathrm{Pd} / \mathrm{D}_{2}$ & 185 & $n, \mathrm{NT}_{D}(\mathrm{C})$ & $2.0 \times 10^{12}$ & \\
\hline Cuevas $^{55)}$ & $\mathrm{TiD}_{1.5}$ & 134 & $n(102 n / s)$ & $5.4 \times 10^{11}$ & \\
\hline Niedra $^{56)}$ & $\mathrm{Ni} / \mathrm{H} / \mathrm{K}$ & 80 & $Q(11.4 \mathrm{~W})$ & $1.4 \times 10^{9}$ & $5 \mathrm{~km} \times 0.5 \mathrm{~mm} \varphi$ \\
\hline Ohmori' $\left.22^{2 \prime}\right)$ & $\mathrm{Au} / \mathrm{H} / \mathrm{K}$ & 200 & $Q, \mathrm{NT}_{F}(\mathrm{Fe})$ & $\sim 10^{11}$ & (Au plate) \\
\hline $\mathrm{Li}^{57)}$ & $\mathrm{Pd} / \mathrm{D}_{2}$ & 185 & $Q$ & $1.6 \times 10^{12}$ & (Pd wire) \\
\hline Qiao $^{\left.57^{\prime}\right)}$ & $\mathrm{Pd} / \mathrm{H}_{2}$ & 185 & $\mathrm{NT}_{F}(\mathrm{Zn})$ & $3.8 \times 10^{10}$ & ( $40 \%$ NT in 1 year) \\
\hline Bressani $^{\left.58^{\prime}\right)}$ & $\mathrm{Ti} / \mathrm{D}_{2}$ & $\leq 10^{3} ?$ & $n(\varepsilon)$ & $10^{4} \sim 10^{6}$ & (Ti shaving) \\
\hline Miley $^{\left.65^{\prime}\right)}$ & $\mathrm{Ni} / \mathrm{H} / \mathrm{Li}$ & 50 & $\mathrm{NT}_{D}(\mathrm{Fe}, \mathrm{Cr})$, & $1.7 \times 10^{12}$ & \\
\hline
\end{tabular}

In addition to the nuclear transmutations in the CF materials, there are observed changes of radioactivity of unstable nuclei in the CFP. We have given explanation on the stabilization of unstable nuclei (including decay-time shortening) in the CFP as follows (Sec. 2.5.1.1 Decay Time Shortening in [14]).

\subsubsection{Decay-Time Shortening}

In general, the explanations of the mechanisms of the nuclear transmutations by decay $\left(\mathrm{NT}_{\mathrm{D}}\right)$ with absorption of a neutron drop ${ }^{A} Z$ composed of $Z$ protons and $(A-Z)$ neutrons are given by the following reaction formulae:

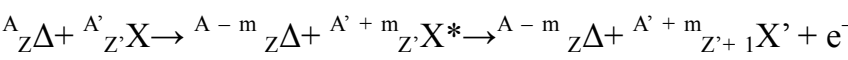

$$
\begin{aligned}
& +v_{\mathrm{e}}+\mathrm{Q} \text {, } \\
& A^{\prime}+m_{Z^{\prime}} X^{*} \rightarrow A^{\prime}+m_{Z^{\prime}+1} X^{\prime}+e^{-}+v_{e}+Q,(\beta) \\
& \mathrm{A}^{\prime}+\mathrm{m}_{\mathrm{Z}} \mathrm{X}^{*} \rightarrow \mathrm{A}^{\prime}+\mathrm{m}-{ }^{4} \mathrm{Z}^{\prime}-{ }_{2} \mathrm{X}^{\prime \prime}+{ }_{2}^{4} \mathrm{He}+\mathrm{Q},(\alpha)
\end{aligned}
$$

Where $\alpha$ and $\beta$ in parentheses designate types of the decay.

In these nuclear transmutations, there are several cases where the decay-times $\tau_{\mathrm{d}}$ of the intermediate compound nuclide ${ }_{\mathrm{Z}}^{\mathrm{A}} \mathrm{X}^{*}$ in free space are very long of orders of $10^{6}$ to $10^{9}$ years $\left(10^{12}-10^{15} \mathrm{~s}\right)$. The time elapsed in experiments is at most several months $\left(\approx 10^{5} \mathrm{~s}\right)$. Therefore, if the decay products with such long decay-times are observed, there should be drastic shortening of the decay-times (or stabilization of unstable nuclei).

Following compound nuclei correspond to this case:

$$
\begin{gathered}
{ }_{46}^{107} \mathrm{Pd}^{*} \rightarrow{ }_{47}^{107} \mathrm{Ag}(\beta) .\left(\tau_{\mathrm{d}}=1.3 \times 10^{9} \mathrm{y}\right) \\
{ }_{19}^{40} \mathrm{~K}^{*} \rightarrow{ }^{40}{ }_{20} \mathrm{Ca}(\beta) . \quad\left(\tau_{\mathrm{d}}=6.5 \times 10^{6} \mathrm{y}\right)
\end{gathered}
$$

\subsubsection{Nuclear Transmutation in Actinoid Hydrides and Deuterides}

Experimental data sets on actinoid hydrides and deuterides prepared by electrolysis and glow discharge [26, 27, 28] have been analyzed and explained using the TNCF model [29]. The experimental data have shown that these hydrides and deuterides are classified as the CF materials where occurs the cold fusion phenomenon (CFP) and the observed events are understood by nuclear reactions common to other reactions observed in CF materials, mainly transition-metal hydrides and deuterides.

The changes of radiation properties of actinoids occluding hydrogen isotopes are explained by formation of the cf-matter similar to the free neutron sea in neutron star matter [30] and then by the interaction of actinoid nucleus and the cf-matter. We have explained the experimental results [26, 27, 28] on the acceleration of the alpha decay of ${ }^{238}{ }_{92} \mathrm{U}$ into ${ }_{90}^{234} \mathrm{Th}$, the so-called the decay-time shortening, by the change of the boundary layer between the nucleus ${ }^{238}{ }_{92} \mathrm{U}$ and the cf-matter. The change of the boundary layer is induced by the increase of the density ratio $n_{\mathrm{o}} / n_{\mathrm{i}}$ of neutrons $\left(n_{i}\right.$ and $n_{\mathrm{o}}$ are neutron densities inside and outside the nucleus, respectively) due to the formation of the cf-matter (Sec. 2.9 in [29]).

A possible application of this phenomenon to ${ }_{94}^{A} \mathrm{Pu}(A=238$ -244 ) is hopeful. If we can handle plutonium isotopes properly, which are produced in atomic plants as hazardous waste, to accelerate their decay, it is the savior of our age from the dangerous nuclear waste waiting its resolution. As shown in Table 4, plutonium isotopes have very long decay-times and therefore the decay-time shortening as shown in the CFP will be applicable to transmute them into other nuclides easy to treat. 
Table 4. Decay characteristics of plutonium isotopes ${ }_{94}^{A} P u$. Decay modes, Half-life (years), Decay heat (W/kg) and Number of spontaneous fission neutrons (per $g \cdot \sec$ ) are given.

\begin{tabular}{llll}
\hline Isotope Decay mode & Half-life (y) & Decay heat (W/kg) & Spon. fission n's (1/g•sec) \\
\hline${ }^{238}{ }_{94} \mathrm{Pu}$ alpha to ${ }^{234}{ }_{92} \mathrm{U}$ & 87.74 & 560 & 2600 \\
${ }^{239}{ }_{94} \mathrm{Pu}$ alpha to ${ }^{235}{ }_{92} \mathrm{U}$ & 24100 & 1.9 & 0.022 \\
${ }^{240}{ }_{94} \mathrm{Pu}$ alpha to ${ }^{236}{ }_{92} \mathrm{U}$ & 6560 & 6.8 & 910 \\
+ Spont. Fission & & & 0.049 \\
${ }^{241}{ }_{94} \mathrm{Pu}$ beta to ${ }^{241}{ }_{95} \mathrm{Am}$ & 14.4 & 4.2 & 1700 \\
${ }_{242}{ }_{94} \mathrm{Pu}$ alpha to ${ }^{238}{ }_{92} \mathrm{U}$ & 376000 & 0.1 & \\
\hline
\end{tabular}

Instead of neutron bombardment in free space, we can use the cf-materials to give an effect of neutrons on target nuclei (cf. [31]). This fact may be interesting in science and technology of the neutron-nuclear interaction in low energy region. It is a pleasant fantasy to imagine a machine simultaneously remediates the radioactive waste and generates excess energy.

\subsection{Nuclear Transmutations in the Composite and Compound CF Materials}

In the recent papers presented at JCF21, we have summarized and analyzed nuclear transmutations observed in the composite (alloys and ceramics) and compound (including boundaries between different components) CF materials [16, $24,25]$. Several of most interesting works in these genres are works by Miley et al. [32, 33], by Kitamura et al. [5] by Celani et al. [7], and by Iwamura et al. [8] which have been extensively treated in our papers cited above.

\section{Nuclear Transmutation in the CF Materials (2) - Polymers and Biological Systems}

The nuclear reactions in the CFP are not confined in the CF materials composed of transition metals/alloys and hydrogen isotopes but also in polymers and biological systems composed of regular arrays of carbon and hydrogen. We have given explanations of a few events of nuclear reactions in polymers and biological systems $[34,35,36]$ using the same idea used to analyze the CFP analyzed in Section 3.

One of the characteristics of these materials is the beforehand existence of the superstructure of $\mathrm{C}$ and $\mathrm{H}$ in the system different from the self-organization of the superlattice of transition metals/alloys and hydrogen isotopes in the transition metal/alloy hydrides/deuterides discussed in Section 3. This characteristic of the polymers and biological systems seems an advantage in realizing the necessary and sufficient condition for the CFP over the CF materials considered in Section 3.

A characteristic of biological systems wherein selective adsorption of specific ions occurs seems very useful for the CFP especially in its application for remediation of hazardous nuclear wastes. If we have a microorganism or microbial culture absorbing an ion of a radioactive element selectively, we can effectively remediate the radioactivity by biotransmutation.

\subsection{Nuclear Transmutation in XLPE}

Similarly, we can contemplate appearance of neutron bands in XLPE shown in Figure 1 [37]. The rather regular structure of the carbon-hydrogen array in XLPE suggests similar mechanism to form the neutron bands as discussed in our recent papers [34, 37]. The atomic arrays in biological cells are more complex compared with that in XLPE as seen in Sec. 5.2 but we may be able to use the same idea used in the CFP general in biological systems.

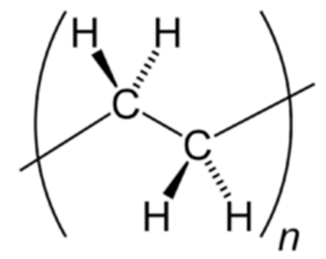

Unit of polyethylene $\left(\mathrm{C}_{2} \mathrm{H}_{4}\right)_{\mathrm{n}}(n=\infty)$.

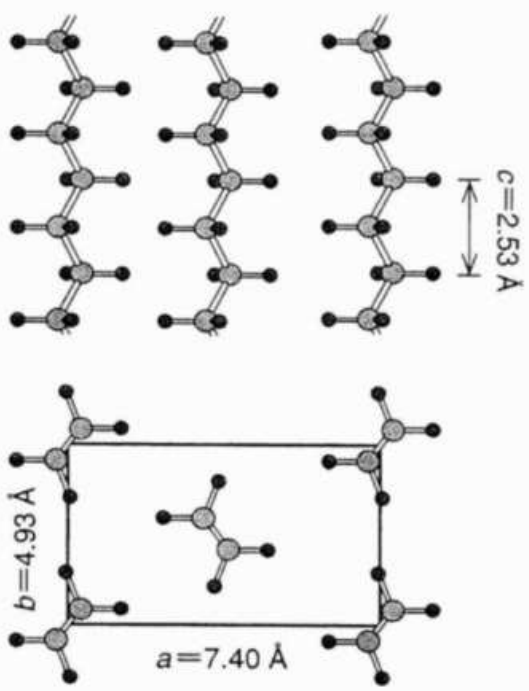

Lattice structure of XLPE.

Figure 1. Lattice structure of XLPE orthorhombic lattice with lattice constants, $a=7.40 \AA$ (740 pm), $b=4.93 \AA$ (493 pm), $c=2.53 \AA$ (253 pm) (Figure 5 in [37]).

Then, we can explain the nuclear transmutations in XLPE observed by the excellent experiments by Kumazawa et al. for more than 10 years from $2005([38,39,40])$ as shown in our papers [34, 37]. For the illustration of nuclear transmutations in their systems including XLPE, we show a data in Table 5 from our paper (Table 2 in [37]). 
Table 5. Increase (+) and decrease (-) of inorganic elements in samples after voltage application (Table 2 in [37]).

\begin{tabular}{|c|c|c|c|c|}
\hline \multirow{2}{*}{ Element } & \multirow{2}{*}{ Isotopes } & \multicolumn{3}{|l|}{ Sample } \\
\hline & & Dipped in KCI solution & Dipped in $\mathrm{NaCl}$ solution & Dipped in $\mathrm{AgNO}_{3}$ solution \\
\hline${ }_{3} \mathrm{Li}$ & ${ }^{6} \mathrm{Li},{ }^{7} \mathrm{Li}$ & & & + \\
\hline${ }_{11} \mathrm{Na}$ & ${ }^{23} \mathrm{Na}$ & & & $(+)$ \\
\hline${ }_{12} \mathrm{Mg}$ & ${ }^{24} \mathrm{Mg},{ }^{25} \mathrm{Mg},{ }^{26} \mathrm{Mg}$ & & & \\
\hline${ }_{13}^{12} \mathrm{Al}$ & ${ }^{27} \mathrm{Al}$ & & & \\
\hline${ }_{19} \mathrm{~K}$ & ${ }^{39} \mathrm{~K},{ }^{40} \mathrm{~K},{ }^{41} \mathrm{~K}$ & & & \\
\hline${ }_{20} \mathrm{Ca}$ & ${ }^{40} \mathrm{Ca},{ }^{42} \mathrm{Ca},{ }^{43} \mathrm{Ca},{ }^{44} \mathrm{Ca},{ }^{46} \mathrm{Ca},{ }^{48} \mathrm{Ca}$ & & & \\
\hline${ }_{26} \mathrm{Fe}$ & ${ }^{54} \mathrm{Fe},{ }^{56} \mathrm{Fe},{ }^{57} \mathrm{Fe},{ }^{58} \mathrm{Fe}$ & & & \\
\hline${ }_{28} \mathrm{Ni}$ & ${ }^{58} \mathrm{Ni},{ }^{60} \mathrm{Ni},{ }^{61} \mathrm{Ni},{ }^{62} \mathrm{Ni},{ }^{64} \mathrm{Ni}$ & & & \pm \\
\hline${ }_{47} \mathrm{Ag}$ & ${ }^{107} \mathrm{Ag},{ }^{109} \mathrm{Ag}$ & & & $(-)$ \\
\hline${ }_{82} \mathrm{~Pb}$ & ${ }^{204} \mathrm{~Pb},{ }^{206} \mathrm{~Pb},{ }^{207} \mathrm{~Pb},{ }^{208} \mathrm{~Pb}$ & & & + \\
\hline${ }_{83} \mathrm{Bi}$ & ${ }^{209} \mathrm{Bi}$ & & & + \\
\hline
\end{tabular}

\subsection{Characteristics of Biotransmutation}

Allowing application of the TNCF model to the problems of biotransmutation, we can use following reactions between a trapped neutron $n$ and a nucleus ${ }^{\mathrm{A}} \mathrm{X}$ at or in the surface of a bacterium or a tissue [35]:

$$
{ }_{Z}^{A} \mathrm{X}+n \rightarrow{ }^{A+1}{ }_{Z} \mathrm{X}^{*} \text {. }
$$

In this reaction formula, ${ }^{\mathrm{A}+1} \mathrm{Z}^{*}$ is an excited state of the nucleus ${ }^{\mathrm{A}+1} \mathrm{Z}$. which will decay through following several channels in free space:

$$
\begin{aligned}
& { }^{A+1}{ }_{Z} \mathrm{X}^{*} \rightarrow{ }^{A+1}{ }_{Z} \mathrm{X}+\gamma, \\
\rightarrow & { }^{A+1}{ }_{Z+1} \mathrm{Y}+e^{-}+v_{\mathrm{e}}, \\
& \rightarrow{ }^{A+1} Z-{ }_{1} \mathrm{Y}^{\prime}-e^{-}, \\
\rightarrow & { }^{A-}{ }_{Z}{ }_{Z}-{ }_{2} \mathrm{Y}^{\prime}+{ }_{2}^{4} \mathrm{He},
\end{aligned}
$$

where $v_{\mathrm{e}}$ is an anti-particle of the electron neutrino, $\gamma$ is a photon (in free space) and $\mathrm{Y}, \mathrm{Y}$ ' and $\mathrm{Y}$ " are daughter nuclides of the reactions. In the CF materials, the photon $\gamma$ in the free space is supposed to be absorbed by the cf-matter formed of neutrons in the neutron band and its energy dissipates in phonons to heat the system as a whole (Section 3.7.5 in [14]).

\subsubsection{Recent Experimental Data on the Biotransmutation Obtained by Vysotskii et al}

V. I. Vysotskii and his collaborators have performed sophisticated experiments and obtained refined data sets in biological systems in these about 20 years mainly by as cited in our paper [34]. To realize the complex structure of microorganisms and microbial cultures used in their experiments, we give their fundamental structures in Figure 2. The structure of cell walls in microbial cultures depicted in Figure 2 (c) show complex but similar regular structures to that in XLPE shown in Figure 1.

There are data sets showing (1) production of ${ }_{26}^{57} \mathrm{Fe}$ from ${ }_{25}^{55} \mathrm{Mn}$ and also (2) acceleration of the decay of radioactive nucleus ${ }^{157}{ }_{55} \mathrm{Cs},{ }_{56}^{140} \mathrm{Ba}$ and ${ }_{57}^{140} \mathrm{La}$ in several bacterial cultures.

Experiments were conducted using several bacterial cultures (Bacillus subtilis GSY 228, Escherichia coli K-1,
Deinococcus radiodurans $M-1$ ) as well as the yeast culture Saccharomyces cerevisiae T-8. Selection of these cultures was motivated either by their experimentally proven ability to grow in the heavy water based media or by the prospect of using the radiation-stable culture Deinococcus radiodurans $M-1$ in transmutation processes given the presence of powerful radioactive fields, as was noted earlier [41].

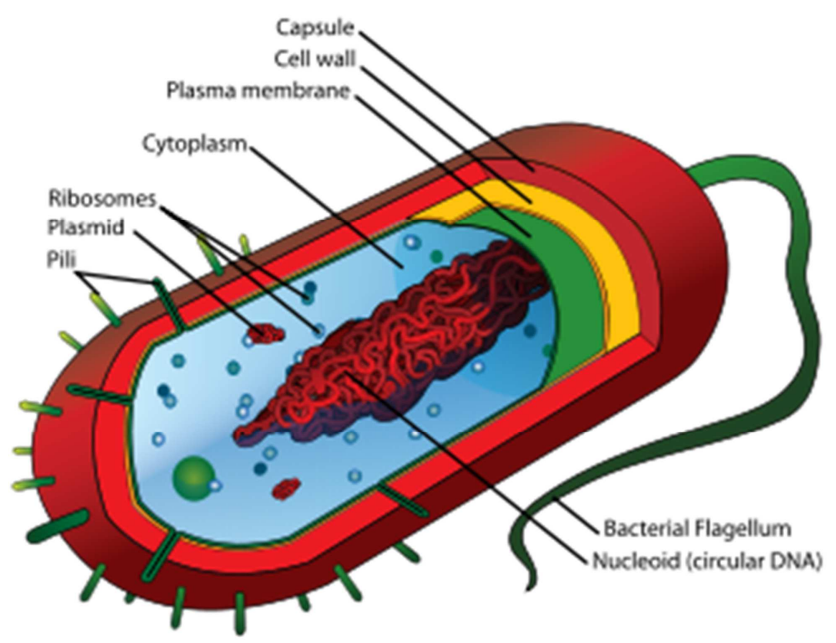

(a) Cell structure of a gram positive bacterium.

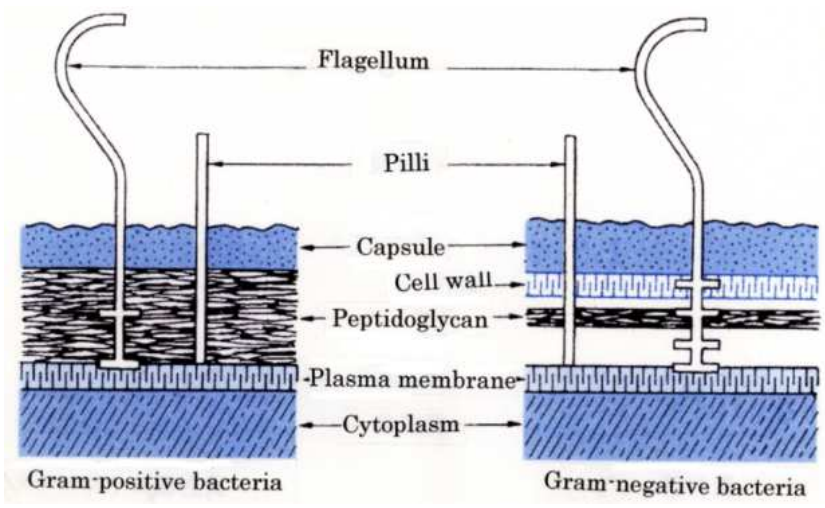

(b) Structures of cell walls in gram-positive and gram-negative bacteria. 


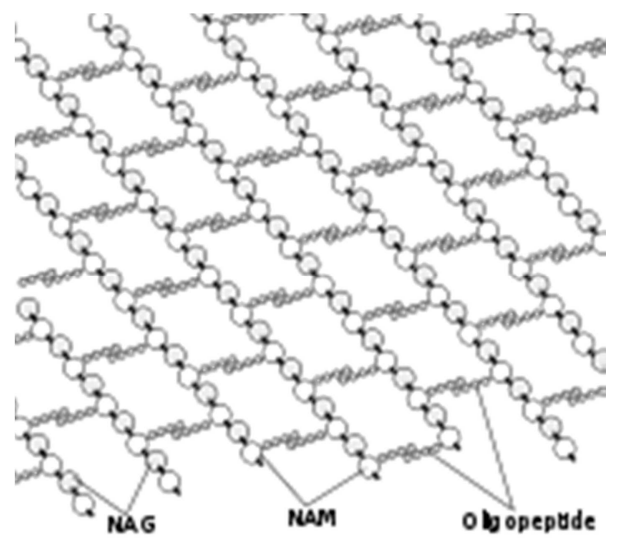

(c) The structure of peptidoglycan.

Figure 2. (a) Cell structure of a gram positive bacterium and (b) structures of cell walls in gram-positive and gram-negative bacteria and (c) structure of peptidoglycan (after Wikipedia).

\subsubsection{Production of ${ }_{26}^{57}$ Fe in a CF Material Containing ${ }_{25}^{55} \mathrm{Mn}$}

The first example is the production of ${ }_{26}^{57} \mathrm{Fe}$ in a $\mathrm{CF}$ material containing ${ }_{25}^{55} \mathrm{Mn}$. The nuclear reaction responsible to this case is suggested by (17) and (16). We can explain the production of ${ }_{26}^{57} \mathrm{Fe}$ from ${ }_{25}^{55} \mathrm{Mn}$ by the following reactions based on the TNCF model (Section 3.1 in [32]):

$$
\begin{array}{r}
{ }_{25}^{55} \mathrm{Mn}+n \rightarrow{ }_{25}^{56} \mathrm{Mn}^{*},(\sigma=13.41 \mathrm{~b}) \\
{ }_{25}^{56} \mathrm{Mn} * \rightarrow{ }_{26}^{56} \mathrm{Fe}+e^{-}+v_{\mathrm{e}},(\tau=2.5785 \mathrm{~h}) \\
{ }_{26}^{56} \mathrm{Fe}+n \rightarrow{ }_{26}^{57} \mathrm{Fe},(\sigma=2.5914 \mathrm{~b})
\end{array}
$$

\subsubsection{Decay-Time Shortening in Biological System}

The observed acceleration of the decay process of ${ }^{137}{ }_{55} \mathrm{Cs}$ isotope is shown in Figure 3. The behavior of the decay-time shortening in transition-metal hydrides had been noticed before and discussed in our paper already [42].

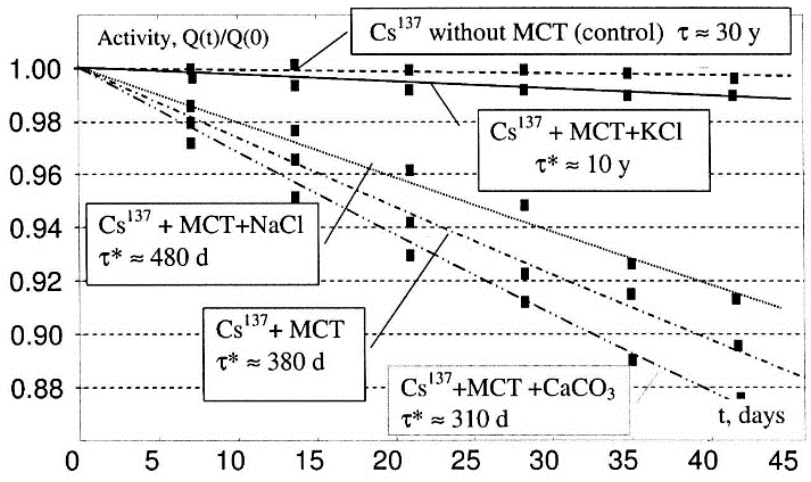

Figure 3. Accelerated deactivation (accelerated decay) of ${ }^{137}{ }_{55}$ Cs isotope in "biological cells" with presents of different chemical elements (Figure 3.23 in [41] and Figure 10 in [43]) "MCT" in the explanation of this figure means the microbial catalyst-transmutator, a special kind of granules.

Another data of the decay-time shortening in the biological system is obtained in ${ }_{56}^{140} \mathrm{Ba}$ and ${ }_{57}^{140} \mathrm{La}$ in pure reactor water with presence of metabolically active microorganisms as shown in Figure 4.

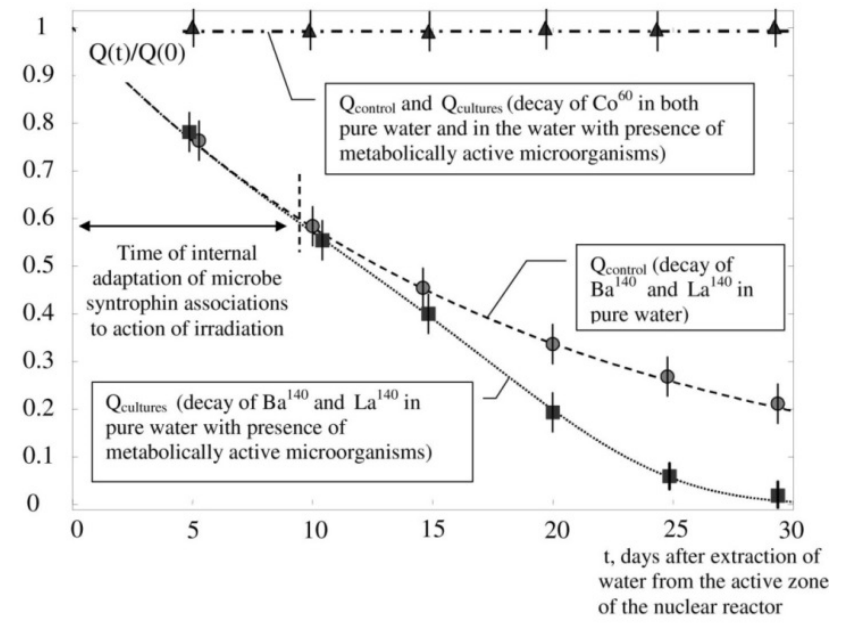

Figure 4. Change of activity $Q(t)$ of the same reactor isotopes ${ }^{140}{ }_{56} \mathrm{Ba},{ }^{140}{ }_{57} \mathrm{La}$ and ${ }_{27}^{60} \mathrm{Co}$ in the experiment on transmutation (activity $Q_{\text {cultures }}$ in pure reactor water with presence of metabolically active microorganisms) and in the control one (activity $Q_{\text {control }}$ in the same pure reactor water without microorganisms) (Figure 3.21 in [41] and Figure 8 in [43]).

\subsubsection{Explanation of Stabilization of Unstable Nuclei (or Decay-Time Shortening) in Biological System}

The sophisticated experiments performed by Vysotskii et al. on the nuclear processes in biological systems revealed existence of the decay-time shortening observed already in inorganic CF systems as discussed recently in our paper [44]. There are two examples of the decay-time shortening in biological system: one for ${ }^{137}{ }_{55} \mathrm{Cs}$ in electrolytic liquid, MCT + electrolyte $\left(\mathrm{KCl}, \mathrm{NaCl}\right.$, or $\left.\mathrm{CaCO}_{3}\right)$, and another for ${ }^{140}{ }_{56} \mathrm{Ba}$ and ${ }_{57}^{140} \mathrm{La}$ in electrolytic liquid (water + metabolically active microorganisms). Explanation of MCT used in the experiment is given elsewhere (Appendix 2 in [35]).

(i). ${ }^{137}{ }_{55} \mathrm{Cs}$

The second example is the decay-time shortening of radioactive isotope ${ }_{55}^{137} \mathrm{Cs}$ which decays in free space according to the following reaction shown in Figure 3:

$$
{ }_{55}^{137} \mathrm{Cs} \rightarrow{ }_{56}^{137} \mathrm{Ba}+e^{-}+v_{\mathrm{e}},(\tau=30.07 \mathrm{y})
$$

Assuming the existence of the trapped neutron in the TNCF model, we can apply the equation (17) to this case:

$$
\begin{gathered}
{ }_{55}^{137} \mathrm{Cs}+n \rightarrow{ }_{55}^{138} \mathrm{Cs}^{*},(\sigma=0.113 \mathrm{~b}) \\
{ }^{138}{ }_{55} \mathrm{Cs}^{*} \rightarrow{ }^{138}{ }_{56} \mathrm{Ba}+e^{-}+v_{\mathrm{e} .}(\tau=33.41 \mathrm{~m})
\end{gathered}
$$

The difference of the effect of MCT (microbial catalyst-transmutator) + electrolyte $\left(\mathrm{KCl}, \mathrm{NaCl}\right.$, or $\left.\mathrm{CaCO}_{3}\right)$ on the decay-time shortening may express (1) difference of the density of the trapped neutrons $n_{\mathrm{n}}$ or (2) difference of the number of ${ }_{55}^{137} \mathrm{Cs}$ nuclei on the MCT surface in the system due to the effect of electrolytic liquids (MCT + electrolytes) on the MCT.

The difference of measured decay times $\tau^{*}=380 \mathrm{~d}$ (MCT), $10 \mathrm{y}(\mathrm{MCT}+\mathrm{KCl}), 480 \mathrm{~d}(\mathrm{MCT}+\mathrm{NaCl})$, and $310 \mathrm{~d}(\mathrm{MCT}+$ $\mathrm{CaCO}_{3}$ ) compared to the natural decay time 30.1 y of ${ }_{55}^{137} \mathrm{Cs}$ in free state shows the effect of the electrolytes on MCT 
where ${ }^{137}{ }_{55} \mathrm{Cs}$ nuclei are adsorbed and their decay characteristics are drastically influenced by the density of the trapped neutron in samples from our point of view. Thus, the electrolyte seems to have large effect on the adsorption characteristics of ${ }^{137}{ }_{55} \mathrm{Cs}$ by MCT.

This fact reminds us the effect of $\mathrm{K}$ and $\mathrm{Li}$ on the CFP in $\mathrm{Ni}$ and Pd discussed by us for many years (e.g., Sec. 2.2.1.2 in [14] and Sec. 4 in [45]).

"It should be emphasized here that there is preference for combination of a cathode metal ( $\mathrm{Pd}, \mathrm{Ni}, \mathrm{Ti}, \quad-\mathrm{C}^{-}$, an electrolyte ( $\mathrm{Li}, \mathrm{Na}, \mathrm{K}$, or $\mathrm{Rb}$ ) and a solvent $\left(\mathrm{D}_{2} \mathrm{O}\right.$ or $\left.\mathrm{H}_{2} \mathrm{O}\right)$ to induce CFP. " (p. 45 in [45]).

Now, let us investigate the characteristics of the decay-time shortening of ${ }_{55}^{137} \mathrm{Cs}$ in these systems.

The temporal evolution of the number of a radioactive nuclide with a decay constant $\tau$ is described by following equations:

$$
\begin{gathered}
N(t)=N(0) \exp (-t / \tau) \\
\mathrm{d} N / \mathrm{d} t=-(N(0) / \tau) \exp (-t / \tau)
\end{gathered}
$$

On the other hand, decrease of the number of a nucleus ${ }_{Z}^{A} \mathrm{X}$ due to absorption of thermal neutrons described by Eq. (28) and the relation (29) assumed in our model (Sec. 11.1 in [13], Sec. 3.2 in [14]):

$$
\begin{gathered}
{ }_{Z}^{A} \mathrm{X}+n={ }_{Z}^{A} \mathrm{X}^{*}={ }^{A+1}{ }_{Z} \mathrm{X}+\text { phonons. } \\
P=\delta N_{X} / N_{\mathrm{X}}=0.35 n_{\mathrm{n}} v_{\mathrm{n}} \sigma_{\mathrm{nX}},
\end{gathered}
$$

In the above equations, $n_{\mathrm{n}}$ is the density of the trapped neutron, $v_{\mathrm{n}}$ is the thermal velocity of the assumed trapped neutron, $N_{\mathrm{X}}$ is the number of the nucleus ${ }_{\mathrm{Z}}^{A} \mathrm{X}$, and $\sigma_{\mathrm{nX}}$ is the absorption cross section of thermal neutrons by the nucleus $\mathrm{X}$ by the reaction (28) $\left(\sigma_{\mathrm{nX}}=0.113 \mathrm{~b}\right.$ for $\left.{ }^{137}{ }_{55} \mathrm{Cs}\right)$ assumed to be the same as the thermal neutron absorption cross section in free space. We use a value $2.2 \times 10^{5} \mathrm{~cm} / \mathrm{s}$ for $v_{\mathrm{n}}$ according to our premises of the TNCF model.

If an ${ }_{55}^{137} \mathrm{Cs}$ nucleus is adsorbed by the MCT granules to be reacted by the trapped neutron, the reaction (28) is written down as,

$$
{ }_{55}^{137} \mathrm{Cs}+n={ }_{55}^{138} \mathrm{Cs} *={ }_{55}^{138} \mathrm{Cs}+\text { phonons. }
$$

The reaction occurs with a probability $P$ in a unit time interval for a nucleus ${ }_{55}^{137} \mathrm{Cs}$ as expressed in Eq. (29):

$$
P=\delta N_{C s} / N_{\mathrm{Cs}}=0.35 n_{\mathrm{n}} v_{\mathrm{n}} \sigma_{\mathrm{nCs}} .
$$

Let us determine the density $n_{\mathrm{n}}$ of the TNCF model assuming that the observed decay-time shortenings of ${ }^{137} \mathrm{Cs}$ in electrolytic liquids depicted in Figure 3 are the results of the neutron absorption described by Eq. (30).

For an example of calculation, we take up the case of ${ }_{55}^{137} \mathrm{Cs}$ in an electrolytic liquid with $\mathrm{MCT}+\mathrm{CaCO}_{3}$, where observed the decay time $\tau^{*}=310 \mathrm{~d}$. Using Eq. (27), we obtain the relative number of decayed nucleus in a unit time (1 day for instance) as

$$
\delta N / N=-\left(1 / \tau^{*}\right) \exp \left(-t / \tau^{*}\right)=-1 /\left(310 \times 8.64 \times 10^{4}\right)=-
$$

$$
1 / 2.68 \times 10^{7}=3.73 \times 10^{-8} .
$$

In this calculation, we notice that the exponential factor $\exp \left(-t / \tau^{*}\right) \approx 1$ and does not essentially contribute to the final result.

On the other hand, the equation (31) gives $n_{\mathrm{n}}$ through the relative number of transmuted ${ }_{55}^{137} \mathrm{Cs}$ nuclei $\delta N / N$ as:

$n_{\mathrm{n}}=(\delta N / N) /\left(0.35 \times 2.2 \times 10^{5} \times 0.113 \times 10^{-24}\right) \times 1(\mathrm{~s})=(\delta N / N) /(0.35$$$
\left.\times 2.2 \times 0.113 \times 10^{-19}\right)=1.15 \times 10^{19}(\delta N / N)
$$

Using the value of $\delta N / N$ given in Eq. (32), we obtain the value of $n_{\mathrm{n}}$ in this case as

$n_{\mathrm{n}}=3.73 \times 10^{-8} / 8.70 \times 10^{-19}=4.29 \times 10^{11} \mathrm{~cm}^{-3}$

If the number of ${ }^{137}{ }_{55} \mathrm{Cs}$ adsorbed by MCT granules and that not adsorbed are in the ratio $x:(1-x)$, the calculation should be generalized to take into this fact. In the short time (e.g. 1 day) we are interested in, the number $N_{0}$ of ${ }_{55}^{137} \mathrm{Cs}$ nuclei not adsorbed and therefore not influenced by the trapped neutron keeps its number $(1-x) N_{0}$ almost the same as before (for the very long decay time of $\tau_{0}=30.1 \mathrm{y}$ ):

$$
\delta N /\left.N\right|_{1}=0 .
$$

On the other hand, the nuclei adsorbed by MCT granules will suffer the action of the trapped neutron and its number $\mathrm{x} N_{0}$ changes according to the equation (31):

$$
\delta N /\left.N\right|_{2}=0.35 \quad n_{\mathrm{n}} v_{\mathrm{n}} \sigma_{\mathrm{nM}} .
$$

Therefore, we have the change $\delta N_{0}$ of the number $N_{0}$ of ${ }_{55}^{137} \mathrm{Cs}$ nuclei after the time interval $t$ ( $=1$ day) given by $\left.\delta N\right|_{1}$ due to the decay process (27) with $\tau=30.1 \mathrm{y}$ and by $\left.\delta N\right|_{2}$ due to the neutron trapping (31). Using the relations (35) and (36), we obtain finally the expression for $\delta N_{0} / N_{0}$ as given in Eq. (38):

$$
\begin{array}{r}
\delta N_{0}=\left.\delta N\right|_{1}+\left.\delta N\right|_{2}=\left.\delta(1-x) N_{0}\right|_{1}+\left.\delta x N_{0}\right|_{2} \\
\delta N_{0} / N_{0}=x\left(\left.\delta N_{0}\right|_{2} / N_{0}\right)=x\left(0.35 n_{\mathrm{n}} v_{\mathrm{n}} \sigma_{\mathrm{nM}}\right)
\end{array}
$$

Substituting the values $v_{\mathrm{n}}=2.2 \times 10^{5} \mathrm{~cm} / \mathrm{s}$ and $\sigma_{\mathrm{nM}}=0.113$ $\mathrm{b}$, we obtain following equation:

$$
\begin{gathered}
\delta N_{0} / N_{0}=x n_{\mathrm{n}}\left(0.35 \times 2.2 \times 10^{5} \times 0.113 \times 10^{-24}\right) \\
=8.7 \times 10^{-21} x n_{\mathrm{n}}
\end{gathered}
$$

Therefore, the value $n_{\mathrm{n}}$ in this case is expressed as

$$
n_{\mathrm{n}}=1.15 \times 10^{19}(\delta N / N) x^{-1}\left(\mathrm{~cm}^{-3}\right)
$$

If $x=1$, i.e. all the ${ }^{137}{ }_{55} \mathrm{Cs}$ nuclei are adsorbed by MCT granules and influenced by the trapped neutron by Eq. (30), $\delta N / N=3.73 \times 10^{-8}(32)$ gives the same value given in (34):

$$
\begin{aligned}
n_{\mathrm{n}} & =1.15 \times 10^{19}(\delta N / N) x^{-1} \\
& =4.29 \times 10^{11}\left(\mathrm{~cm}^{-3}\right) .
\end{aligned}
$$

This value is compared with the values $10^{7}-10^{12} \mathrm{~cm}^{-3}$ obtained in inorganic CF materials tabulated in Tables 2 and 


\section{3 in Section 4.}

As the Eq. (27) (or Eq. (32)) shows that the decrease of the number of radioactive nuclei is proportional to the decay time $\tau^{*}$ inversely and it is also proportional to $x$ and $n_{\mathrm{n}}$ as shown by Eq. (38) (where $x$ is the ratio of adsorbed nuclei). The differences of $\tau^{*}$ observed in different electrolytic liquids are explained as follows.

If the density of trapped neutrons $n_{\mathrm{n}}$ is not influenced by the kind of electrolyte in the liquid, the difference of $\tau^{*}$ depend only on the value of $\mathrm{x}$ which may depend on the electrolyte. The values of $\tau^{*}=310 \mathrm{~d}, 380 \mathrm{~d}, 480 \mathrm{~d}, 10 \mathrm{y}$ in the liquid with $\mathrm{CaCO}_{3}$, non, $\mathrm{NaCl}, \mathrm{KCl}$, respectively, show that the ratios $x$ in these electrolytic liquids are given by $1,0.8,0.6,8.5 \times 10^{-3}$, respectively taking the case of $\mathrm{CaCO}_{3}$ as $x=1$.

This result may show the aqueous solution of MCT granules is very effective to adsorb ${ }^{137}{ }_{55} \mathrm{Cs}$ nucleus (and change the value of $x$ ) and addition of $\mathrm{CaCO}_{3}$ works positively but that of $\mathrm{NaCl}$ and $\mathrm{KCl}$ negatively to the adsorption, if our interpretation by the TNCF model of the decay-time shortening in the electrolytic liquids is right.

(ii). ${ }_{56}^{140} \mathrm{Ba}$ and ${ }^{140}{ }_{57} \mathrm{La}$

Similarly, we can analyze the cases of ${ }_{56}^{140} \mathrm{Ba}$ and ${ }_{57}^{140} \mathrm{La}$ shown in Figure 4. The decays of these nuclides are described by the following formulae:

$$
\begin{gathered}
{ }_{56}^{140} \mathrm{Ba} \rightarrow{ }_{57}^{140} \mathrm{La}+e^{-}+v_{\mathrm{e}}(\tau=12.752 \mathrm{~d}) \\
{ }_{57}^{140} \mathrm{La} \rightarrow{ }^{140}{ }_{58} \mathrm{Ce}+e^{-}+v_{\mathrm{e}}(\tau=1.6781 \mathrm{~d})
\end{gathered}
$$

The decay-time shortenings of these nuclides are explained by the absorption of a neutron by ${ }_{56}^{140} \mathrm{Ba}$ and ${ }_{57}^{140} \mathrm{La}$ followed by the beta-decay of the intermediate nuclei as shown below:

$$
\begin{gathered}
{ }_{56}^{140} \mathrm{Ba}+n \rightarrow{ }_{56}^{141} \mathrm{Ba}^{*},(\sigma=1.63 \mathrm{~b}) \\
{ }_{56}^{141} \mathrm{Ba}^{*} \rightarrow{ }^{141}{ }_{57} \mathrm{La}+e^{-}+v_{\mathrm{e}}(\tau=18.27 \mathrm{~m})
\end{gathered}
$$

and

$$
\begin{gathered}
{ }_{57}^{140} \mathrm{La}+n \rightarrow{ }_{56}^{141} \mathrm{La}^{*},(\sigma=2.73 \mathrm{~b}) \\
{ }_{56}^{141} \mathrm{La}^{*} \rightarrow{ }_{58}^{141} \mathrm{Ce}+e^{-}+v_{\mathrm{e}}(\tau=3.92 \mathrm{~h})
\end{gathered}
$$

On the other hand, the decay of ${ }_{27}^{60} \mathrm{Co}$ is not intensified measurably by the existence and absorption of the trapped neutrons as shown by following equations:

$$
\begin{gathered}
{ }_{27}^{60} \mathrm{Co} \rightarrow{ }_{58}^{60} \mathrm{Ni}+e^{-}+v_{\mathrm{e}}(\tau=10.47 \mathrm{~m}) \\
{ }^{60}{ }_{27} \mathrm{Co}+n \rightarrow{ }^{61}{ }_{27} \mathrm{Co}^{*}(\sigma=2.02 \mathrm{~b}) \\
{ }^{61}{ }_{27} \mathrm{Co}^{*} \rightarrow{ }^{61}{ }_{58} \mathrm{Ni}+e^{-}+v_{\mathrm{e}}(\tau=1.65 \mathrm{~h})
\end{gathered}
$$

Thus, the experimental data sets obtained for ${ }_{56}^{140} \mathrm{Ba}$, ${ }_{57}^{140} \mathrm{La}$ and ${ }_{27}^{60} \mathrm{Co}$ shown in Figure 4 are consistently explained by the TNCF model.

\subsection{Other Biotransmutations}

About the data of biotransmutations known since $18^{\text {th }}$ century, let us quote some sentences related with our investigation from page 25 of Michio Kushi's book [46]. The elemental transmutation (ET) in biological systems is considered as "most likely taking place at the cellular level."

". - - it was concluded that, granted the existence of transmutations ( $\mathrm{Na}$ to $\mathrm{Mg}, \mathrm{K}$ to $\mathrm{Ca}, \mathrm{Mn}$ to $\mathrm{Fe}$ ), then a net surplus of energy was also produced."

"A proposed mechanism was described in which $\mathrm{Mg}$ adenosine triphosphate (MgATP) played a double role as an energy producer." "The MgATP, when placed in layers one atop the other, has all the attributes of a cyclotron."

"It was concluded that elemental transmutations were indeed occurring in life organs and were probably accompanied by a net energy gain.” (p. 25 in [46]).

This summary of the biotransmutations by M. Kushi is based on many observations by Vauquelin and others which are introduced in our paper [47] and book (Sec. 10.1 Biotransmutation in [13]).

\subsection{Characteristics of Biotransmutations Applicable to the Remediation of the Hazardous Nuclear Waste}

In inorganic systems used in the CFP, it is known that there are specific favorable combinations of an electrode and an electrolyte to realize the CFP in electrolytic experiments: $\mathrm{Pd}-\mathrm{Li}$ and $\mathrm{Ni}-\mathrm{K}$ are the most outstanding pairs used in positive experiments for the CFP [45].

It might be possible to have a biological system in which the CF material (e.g. a bacterium) adsorbs selectively a specific element on the surface by the nature of the surface or of the material. Then if the bacterium works as an agent similar to the MCT in Figure 3, the system is applicable to remediate effectively hazardous radioactive waste.

Solid State-Nuclear Sciences

It should be noticed that the nuclear reaction in the $\mathrm{CF}$ materials at around room temperature observed in the CFP has its counterpart in the physics and chemistry of the $\mathrm{CF}$ materials even if there have no nuclear reactions but fingerprints in the behavior of protons/deuterons and also in the states of lattice nuclei. These problems have only its preliminary investigation now (e.g., $[20,24,48]$ ) but show profound and fruitful future developments.

\section{Conclusion}

The nuclear reactions in the specific solids having a superlattice composed of a sublattice of some elements having characteristic nuclear structure and another sublattice of hydrogen isotopes at around room temperature have been discovered by chance in 1989 in a research of the excess energy generation in $\mathrm{PdD}_{\mathrm{x}}$ alloys $(\mathrm{x} \lesssim 1)$ with an excessive or rather erroneous expectation of the $d-d$ fusion reactions there [1].

Very many research works followed the pioneering paper by Fleischmann et al. have revealed reality of the nuclear reactions in the CF materials (various transition metal/alloy hydrides/deuterides) at around room temperature up to $1000^{\circ} \mathrm{C}$ with events generating transmuted nuclei from small masses as neutron, triton, helium-4 to large masses ${ }_{83}^{209} \mathrm{Bi},{ }_{84}^{208} \mathrm{~Pb},--$ The experimental data obtained in these more than 30 years since 1989 show clearly there are some mechanisms not noticed 
before inducing the nuclear reactions observed in the CFP.

One of the approaches successful to give a consistent explanation for the whole heap of data has been given by our TNCF model constructed phenomenologically using several premises in which is an adjustable parameter $n_{\mathrm{n}}$, a density of the "trapped neutrons" in the CF material. As summarized in Section 3, the model has been successful to give qualitative, sometimes even more semi-quantitative explanations for events observed in the CFP.

The premises including the existence of the trapped neutrons have been investigated and verified quantum mechanically using such knowledge obtained in nuclear physics as the exotic nuclei and in transition metal hydrides/deuterides as super-diffusivity. The TNCF model successfully applied to the original CF materials composed of transition metal/alloy hydrides/deuterides have been used in the investigation of the CFP in the CF materials composed of polymers and biological systems with hopeful results to explain the events observed in them consistent to the explanation given in the original CF materials.

Then, we can extend our investigation using the TNCF model to other physical and chemical phenomenon than the CFP, i.e. the cold fusion phenomenon. There are several such big genres investigated for long times as the super-diffusion of hydrogen (in transition metal/alloy hydrides), the hydrogen electrode reaction (HER) and the underpotential deposition (UPD) (in electrochemistry), the exotic nuclei with large excess of neutron numbers over the proton numbers isolated in free space (in nuclear physics). The nuclear reactions in the CFP as explained by our model using the super-nuclear interaction between neutrons in different lattice nuclei (cf. [14] $[17,20]$, and [29]) might be useful to investigate the unsolved riddles encountered in these research fields listed up above and also to develop a new phase in the situation where are interactions with other nuclides.

The nuclear-force interaction revealed its existence in the $\mathrm{CF}$ material will induce a great impact on many sciences including materials with similar properties to the CF material where the occluded protons/deuterons have extended wavefunctions to overlap with the lattice nuclei.

\section{Acknowledgements}

The author would like to give his sincere thanks to many people who have given him help during the difficult works in this field since 1989. Especially mentioned are the encouragement and supports to him by the late Dr. Koji Husimi, the late Dr. Makoto Okamoto, and the late Dr. John Dash who watched and helped his work with their warm eyes through their lives.

\section{References}

[1] Fleischmann, M., Pons S., and Hawkins, M. (1989) Electrochemically induced nuclear fusion of deuterium, $J$. Electroanal. Chem., 261, 301-308.
[2] Jones, E. P. Palmer, E. P., Czirr, J. B., Decker, D. L., Jensen, G L., Thorne, J. M. and Tayler, S.E., "Observation of Cold Nuclear Fusion in Condensed Matter," Nature 338, 737-740 (1989).

[3] Packham, N. J. C., Wolf, K. L., Wass J. C., Kainthla, R. C. and Bockris, J.O'M. (1989) Production of tritium from $\mathrm{D}_{2} \mathrm{O}$ electrolysis ant a palladium cathode, J. Electroanal. Chem., 270, 451-458, ISSN 1572-6657.

[4] Morrey, J. R., Caffee, M. R., Farrar IV, H., Hoffman, N. J., et. al. (1990) Measurements of helium in electrolyzed palladium, Fusion Technol., 18, pp. 659-668, ISSN 0748-1896.

[5] Kitamura, A., et al., (2018). Excess heat evolution from nanocomposite samples under exposure to hydrogen isotope gases, Int. J. of Hydrogen Energy, 43. Issue 33, pp. 16187-16200.

[6] V. I. Vysotskii and A. A. Kornilova, “'Biological Transmutation' of Stable and Radioactive Isotopes in Growing Biological Systems," J. Condensed Matter Nuclear Science, 28, pp. 7-20 (2019), ISSN 2227-3123.

[7] Celani, F., Lorenzetti, C., Vassallo, G., Purchi, E., Fiorilla, S., et al. (2020). Progress toward an understanding of LENR-AHE effects in coated constantan wires in $\mathrm{D}_{2}$ atmosphere: DC/AC voltage stimulation, J. Condensed Matter Nucl. Sci., 33, pp. 46-73, ISSN 2227-3123.

[8] Iwamura, Y., Itoh, T., Kasagi, J., Murakami, S., and Saito, M. (2020). Excess energy generation using a nano-sized multilayer metal composite and hydrogen gas, J. Condensed Matter Nucl. Sci., 33, pp. 1-13, ISSN 2227-3123.

[9] Srinivasan, M., Shyam, A., Kaushik, T. C., Rout, R. K., Kulkarni, L. V. et al. (1990) Observation of tritium in gas/plasma loaded titanium samples, AIP Conference Proceedings 228, pp. 1-21. Brigham Young Univ., Provo, UT: American Institute of Physics, New York.

[10] Claytor, T. N., Tuggle, D. G., Menlove, H. O., Seeger, P. A., Doty W. R., and Rohwer, R. K. (1991), Tritium and neutron measurements from deuterated $\mathrm{Pd}-\mathrm{Si}$, AIP Conference Proceedings 228, 467-480. https://doi.org/10.1063/1.40668

[11] Claytor, T. N., Tuggle, D. G., Menlove (1991), Tritium generation and neutron measurements in $\mathrm{Pd}-\mathrm{Si}$ under high deuterium gas pressure, Proc. ICCF2, pp. 395-408, ISBN 88-7794-045-X.

[12] Romodanov, V. A., Savin, V. I., Skuratnik, Y. B. and Timofeev, Y. (1993), Nuclear fusion in condensed matter, Proc, ICCF3, pp. 307-319, ISBN 4-946443-12-6.

[13] Kozima, H. (1998) Discovery of the Cold Fusion Phenomenon Ohtake Shuppan Inc., Tokyo, Japan, 1998. ISBN: 4-87186-044-2.

[14] Kozima, H. (2006), The Science of the Cold Fusion Phenomenon, Elsevier Science, 2006, ISBN-10: 0-08-045110-1.

[15] Kozima, H. (1994), Trapped neutron catalysed fusion of deuterons and protons in inhomogeneous solids, Trans. Fusion Technol. 26, 508 - 515, ISSN 0748-1896.

[16] Kozima, H. (2021), Neutron energy bands in the composite and compound $\mathrm{CF}$ materials-speculation on the bases of the TNCF model -, Proc. JCF21, 21-4, ISSN 2187-2260 (to be published). 
[17] Kozima, H. (2013). Cold Fusion Phenomenon in Open, Nonequilibrium, Multi-component Systems-Self-organization of Optimum Structure, Proc. JCF13 13-19, pp. 134 - 157, ISSN 2187-2260.

[18] Kozima H. and Kaki, K. (2016). The cold fusion phenomenon and neutrons in solids, Proc. JCF16, 16-14, pp. 158-198, ISSN 2187-2260.

[19] Kozima H. and Yamada, H. (2019). Characteristics of the nuclear reactions in the cold fusion phenomenon, Proc. JCF19, 19-13, pp. 165-191, ISSN 2187-2260.

[20] Kozima, H. (2019). Development of the solid state-nuclear physics, Proc. JCF19, 19-15, pp. 112-147, ISSN 2187-2260.

[21] Kozima, H. (2012). Cold fusion phenomenon in open, nonequilibrium, multi-component systems, Reports of CFRL (Cold Fusion Research Laboratory) 12-1, pp. 1-14 (January 2012); http://www.kozima-cfrl.com/Papers/paperr/paperr.html

[22] Kozima, H. (2012). Three laws in the cold fusion phenomenon and their physical meaning, Proc. JCF12, pp. 101-114, ISSN 2187-2260.

[23] Storms, E. (2017). The Science of Low Energy Nuclear Reaction-A Comprehensive Compilation of Evidence and Explanations about Cold Fusion -, World Scientific, Singapore, 2017, ISBN-10 981-270-620-8.

[24] Kozima, H. (2021). Cold fusion phenomenon in the composite $\mathrm{CF}$ materials-mixed hydrogen isotopes, alloys, ceramics and polymers -, Proc. JCF21, 21-2, ISSN 2187-2260, (to be published).

[25] Kozima, H. (2021). Cold fusion phenomenon in the compound CF materials-effects of interface -, Proc. JCF21, 21-3, ISSN 2187-2260, (to be published).

[26] Goddard, G., Dash, J., and Frantz, S. (2000). Characterization of uranium co-deposited with hydrogen on nickel cathodes, Transactions of American Nuclear Soc. 83, 376-378.

[27] Dash, J., Savvatimova, I., Frantz, S., Weis, E., and Kozima, H. (2003). Effects of glow discharge with hydrogen isotope plasmas on radioactivity of uranium, Proc. ICCF9, pp. 77-81. ISBN 7-302-06489-X/O·292.

[28] Dash, J., and Chicea, D. (2005). Changes in the radioactivity, topography, and surface composition of uranium after hydrogen loading by aqueous electrolysis, Proc. ICCF10 pp. 463-474. ISBN 981-256-564-7.

[29] Kozima, H., and Kaki, K. (2014). Atomic nucleus and neutron - Nuclear physics revisited with the viewpoint of the cold fusion phenomenon, Proc. JCF14, 14-5, pp. 47 - 76, ISSN 2187-2260. And also Reports of CFRL (Cold Fusion Research Laboratory) 14-1, 1-34 (March 2014). http://www.kozima-cfrl.com/Papers/paperr/paperr.html

[30] Negele, J. W., and Vautherin, D. (1973). Neutron star matter at sub-nuclear densities, Nuclear Physics, A207, 298-320, ISSN: 0375-9474.

[31] JP 6106892 B2 https://jopss.jaea.go.jp/pdfdata/P2/P14027B.pdf

2017.4.5.

[32] Miley, G. H. and Patterson, J. A. (1996). Nuclear transmutations in thin-film nickel coating undergoing electrolysis, J. New Energy, 1 (3), pp. 5-39, ISSN 1086-8259.

[33] Miley, G. H., Name, G., Williams, M. J., Patterson, J. A., Nix,
J., Cravens, D., and Hora, H. (1996). Quantitative observation of transmutation products occurring in thin-film coated microspheres during electrolysis, Proc. ICCF6, pp. 629-644, NEDO and Institute of Applied Energy, Tokyo, Japan, 1996.

[34] Kozima, H. (2016). Nuclear transmutations in polyethylene (XLPE) films and water tree generation in them (2), Proc. JCF16, 16-17, pp. 210-215, ISSN 2187-2260.

[35] Kozima, H. (2016). Biotransmutation as a cold fusion phenomenon, Proc. JCF16, 16-18, pp. 216-239, ISSN 2187-2260.

[36] Kozima, H. (2019). Nuclear transmutations and stabilization of unstable nuclei in the cold fusion phenomenon, J. CMNS (Condensed Matter Nuclear Science), 28, pp. 28-49, ISSN 2227-3123.

[37] Kozima, H., and Date, H. (2010). Nuclear transmutations in polyethylene (XLPE) films and water tree generation in them, Proc. ICCF 14 (August 10-15, 2008, Washington D. C., U.S.A.), pp. 618-622, ISBN 978-0-578-06694-3.

[38] Kumazawa, T., Nakagawa, W., and Tsurumaru, H. (2005). A study on behavior of inorganic impurities in water tree, Electrical Engineering in Japan 153, 1-13.

[39] Kumazawa, T., Nakagawa, W., and Tsurumaru, H. (2006). Experimental study on behavior of bow-tie tree generation by using heavy water (in Japanese), IEEJ Trans. FM, 126, 863-868.

[40] Kumazawa T., and Taniguchi, R. (2007). Detection of weak radiation involving generation and progress of water tree (in Japanese), IEEJ Trans. FM, 127, 89-96.

[41] Vysotskii, V. I., and Kornilova, A. A. (2009). Nuclear Transmutation of Stable and Radioactive Isotopes in Growing Biological Systems, Pentagon Press, India, 2009.

[42] Kozima, H. (2014). Nuclear transmutations (NTs) in cold fusion phenomenon (CFP) and nuclear physics, Proc. JCF14, 14-15, pp. 168 - 202, ISSN 2187-2260. Also Reports of CFRL (Cold Fusion Research Laboratory), 14-3, 1-35 (March 2014): http://www.kozima-cfrl.com/Papers/paperr/paperr.html.

[43] Vysotskii, V. A., and Kornilova, A. A. (2013). Transmutation of stable isotopes and deactivation of radioactive waste, Annals of Nuclear Energy 62, 626-633.

[44] Kozima, H. (2014). Nuclear transmutation in actinoid hydrides and deuterides, Proc. JCF14, 14-6, pp. 77-94, ISSN $2187-2260$

[45] Kozima, H. (2000). Electroanalytical chemistry in cold fusion phenomenon, in Recent Research Developments in Electroanalytical Chemistry, pp. 35-46, ed. S. G. Pandalai, Transworld Research Network, 2000, ISBN 81-86486-94-8. This paper is posted at the CFRL website: http://www.kozima-cfrl.com/Papers/papere/papere.html

[46] Kushi, M. (1994). The Philosopher's Stone, One Peaceful World Press, 1994.

[47] Kozima, H., Hiroe, K., Nomura, M., and Ohta, M. (1996). Elemental transmutation in biological and chemical systems, Cold Fusion, 16, 30-32, ISSN 1074-5610, http://www.kozima-cfrl.com/Papers/paperc/paperc.html.

[48] Kozima, H. (2021). A sketch of the solid state-nuclear sciences, Proc. ICCF23 (June 9-11, 2021, Fujian, China), (to be published). 